\title{
ESTUDO DA PRECIFICAÇÃO DE COMPANHIAS AÉREAS EM ROTAS DOMÉSTICAS DE LONGO PERCURSO
}

\author{
Daniele Silva Oliveira ${ }^{1}$ \\ Giovanna Miceli Ronzani ${ }^{1}$ \\ Michelle C. G. da S. P. Bandeira ${ }^{1}$ \\ Luciano Santos Lopes ${ }^{1}$ \\ Alessandro V. M. Oliveira ${ }^{2}$
}

\begin{abstract}
Resumo: Este trabalho visa suprir uma carência da literatura nacional, buscando investigar a precificação das companhias aéreas no mercado doméstico de vôos de longo percurso. Foi, assim, realizada uma comparação dos preços de passagens aéreas disponíveis na Internet (web pricing) para algumas rotas selecionadas desse tipo de mercado, e oferecidas pelas três maiores companhias aéreas brasileiras. Os dados coletados foram utilizados para a estimação de uma equação de preços, utilizando-se da hipótese da existência de diferentes segmentos de passageiros. Assim, foi desenvolvida uma classificação de cenários de compra para três tipos estilizados de usuários: viajantes a negócios, turista no feriado e viajante no mês de julho. Esta análise do comportamento dos preços diante de várias situações competitivas das companhias aéreas permite um melhor entendimento dos padrões de competição no setor. Os resultados finais indicaram que: 1. As passagens oferecidas aos viajantes a negócios, as que se referem ao retorno a São Paulo e as que envolvem pouso ou decolagem no Aeroporto de Congonhas são, em geral, as mais caras; 2 . que, contrariamente ao senso comum, os vôos "corujões" apresentaram passagens com preços mais elevados; e 3. que uma companhia aérea em processo de recuperação judicial apresentou-se como a alternativa low fare no mercado, provavelmente por conta da maior necessidade de geração de fluxo de caixa e dos efeitos nos custos incorridos pela proteção contra credores.
\end{abstract}

Palavras-Chave: Transporte Aéreo - Precificação - Internet - Econometria

Abstract: This paper aims at studying the pricing of the airlines in the Brazilian domestic market of long-haul flights, and therefore contributing to the scarce existing literature. It was, therefore, performed a comparison of the available web prices of three major Brazilian airlines' for some selected long-haul routes. Collected data were used for estimation of a price equation. By making use of a classification of purchase sceneries for each stylized type of user - travelers on business, tourist in the holiday, and traveler in July. This analysis of prices behavior due to several competitive situations of the airline companies allows better to understand the competition patterns in the area. The final results indicated that: 1 . The passages offered to the travelers to business, which tell to themselves to the return the Sao Paulo and those who encase landing or takeoff in the Airport of Congonhas are, in general, the most expensive; 2. that an airline company in bankruptcy process presented the smallest prices, probably due to the largest need of cash flow generation and of the protection against creditors; and 3. the main low cost airline company of the area presented larger prices than the others in return trips to São Paulo in the on business and on July traveling sceneries and in trips of the types with scale flighty and non stop.

Key Words: Air Transportation - Pricing - Internet - Econometrics

\footnotetext{
${ }^{1}$ Divisão de Engenharia de Infra-Estrutura Aeronáutica, Instituto Tecnológico de Aeronáutica.

${ }^{2}$ Núcleo de Estudos em Competição e Regulação do Transporte Aéreo (NECTAR), Instituto Tecnológico de Aeronáutica. E-mail: A.V.M.Oliveira@gmail.com. 


\section{Introdução}

O presente trabalho visa estudar a formação de preços no mercado de transporte aéreo doméstico de passageiros, com foco na competição nas rotas de longos percursos no País. A motivação do estudo está na escassez de literatura quanto ao comportamento competitivo das companhias aéreas neste tipo de rota. Estudos referentes à concorrência em rotas de percurso curto podem ser encontrados em Oliveira (2005) e Soares de Mello et al. (2003). O objetivo principal do trabalho é entender e avaliar o grau de competição praticado pelas atuais companhias, suas estratégias de mercado e o papel da diferenciação de produto, neste tipo específico de mercados aéreos.

Com vistas a propiciar uma maior compreensão da precificação no setor foi, assim, realizada uma comparação dos preços de passagens aéreas disponíveis na Internet (web pricing) para algumas rotas selecionadas de longo percurso, e oferecidas pelas três maiores companhias aéreas brasileiras. Os dados coletados foram utilizados para a estimação de uma equação de preços, em um arcabouço econométrico.

Como principal diretriz para o processo de coleta de dados, buscou-se flexibilizar uma hipótese corriqueira nas análises do setor aéreo, que é a existência de um consumidor representativo, assumindo-se, desta forma, a coexistência de diferentes segmentos de passageiros no mercado, como em Bettini et al. (2005). Assim, foi desenvolvida uma classificação de cenários de compra para três tipos estilizados de usuários: viajantes a negócios, turista no feriado e viajante no mês de julho. Foi realizada uma pesquisa utilizando-se questionários junto a potenciais viajantes a negócios em rotas de longo percurso, como forma de melhor embasar a configuração do cenário de viajantes a negócio. Esta análise do comportamento dos preços diante de várias situações competitivas das companhias aéreas tem a potencialidade de permitir um melhor entendimento dos padrões de competição no setor.

Os resultados finais indicaram que: 1. As passagens oferecidas aos viajantes a negócios, as que se referem ao retorno a São Paulo e as que envolvem pouso ou decolagem no Aeroporto de Congonhas são, em geral, as mais caras; 2. que, contrariamente ao senso comum, os vôos "corujões" apresentaram passagens com preços mais elevados; e 3 . que uma companhia aérea em processo de recuperação judicial apresentou-se como a alternativa low fare no mercado, provavelmente por conta da maior necessidade de geração de fluxo de caixa e dos efeitos nos custos incorridos pela proteção contra credores.

\section{O Transporte Aéreo e a Precificação das Operadoras}

O transporte aéreo é um dos setores freqüentemente apontados como estratégicos por governos e também por analistas (Pasin e Lacerda, 2003). Apresenta grande relevância na economia do país, representando aproximadamente $3 \%$ do produto doméstico bruto, e com um impacto total em torno de 18 milhões de dólares (Marchetti et al., 2001). Prova disto, é o item "passagens aéreas", que assume uma importante participação na POF (Pesquisa de Orçamento Familiar) dos índices de inflação e, portanto, tem influência direta na evolução dos preços da economia. Os impactos no crescimento econômico mostram que o setor é altamente elástico à renda, ou seja, em períodos de crescimento econômico, o tráfego aéreo cresce muito mais do que em proporção à renda (PIB). Em atividades que são correlacionadas ao transporte aéreo, por exemplo, o setor de turismo, esses fenômenos tendem a serem mais acentuados, diferentemente do viajante business, que é menos elástico a preço.

No início do século XXI, o cenário da aviação brasileira teve como uma das principais causas da política de flexibilização o surgimento da primeira companhia aérea da América Latina a 
operar no modelo low-cost, low-fare (LCC) - a Gol Linhas Aéreas Inteligentes - com um posicionamento inovador da LCC. Concomitante com a entrada da Gol, em 2001, no período considerado como quase-desregulamentação, entradas, tarifas $\mathrm{e}$ freqüências foram liberalizados completamente, além da afirmação da world wide web, que teve relevante importância como canal de distribuição e comercialização das passagens aéreas. Oferecendo uma estrutura de tarifa muito simples, com preços até $45 \%$ abaixo das competidoras tradicionais, a Gol entra no mercado doméstico com um próspero caminho de crescimento. As empresas desse segmento têm mostrado mais lucrativas que as companhias de modelo tradicional, onde as maiores taxas de lucro na aviação comercial mundial foram observadas em companhias como a Ryanair, a Southwest e até mesmo a Gol (Palladino, 2005). Isto mostra que o modelo low-cost, low-fare tomou algumas medidas que fizeram baixar os valores de suas passagens aéreas.

O modelo LCC provoca uma reação nas atuais full service, e dessa forma, uma maior variabilidade nos preços cobrados pelas diferentes companhias aéreas nos trechos oferecidos. Podemos entender que isto ocasiona um aperfeiçoamento no yield management que vai induzir também a diferenciação do produto. Porém, o plano inicial de operações da Gol, passou por reformas já a partir do seu segundo ano de existência. Deixou de focar ligações ponto-a-ponto, de alta densidade e etapa de vôo curto (Paradigma Southwest), para acrescentar à sua malha um conjunto de ligações de menor densidade, vôos de maior duração e com um número de escalas e conexões, o que não é típico de uma LCC.

E por fim, o atual processo de recuperação judicial em que uma das principais operadoras no mercado - a Varig - se encontra, tem levado ao cancelamento de vôos e rotas, perspectivas de corte de pessoal e arresto de aeronaves, debilidade financeira generalizada, etc. Estes eventos podem afetar a forma de precificação desta companhia aérea. A paralisação gradual da companhia provoca em um curto prazo, aumento médio dos preços das passagens aéreas domésticas, num mercado já pressionado pela maior demanda nas férias de julho, dólar em recuperação e elevação de custos devido ao petróleo.

O presente artigo teve a finalidade de investigar empiricamente a vantagem competitiva nos preços praticados pela TAM, Varig e GOL. Seguindo essa mesma linha, Evans e Kessides (1993) fizeram uso de uma aproximação empírica estudando o comportamento dos preços das companhias aéreas, o que possibilitou descobrir os determinantes do poder de preços na indústria. Para os autores existem duas categorias em estudos de análise empírica que são aproximações para o estudo dos elementos que influenciam o nível das tarifas aéreas. A primeira categoria é a análise "inter-rota", onde se inferem os efeitos das variáveis de estrutura de mercado em preços cross-sectional nas rotas, ou seja, os dados estão desagregados no nível da rota e referemse as variáveis como distância de vôo, número de companhias presentes, etc. A pesquisa segue a segunda categoria, a de análise "intra-rota", nesse caso introduzse a heterogeneidade das empresas que operam em uma rota: características específicas das companhias, quantidades de assentos, etc; dentro dessa análise seguem o Borenstein (1989), Berry (1990), Evans e Kessides (1993) e Oliveira e Huse (2005).

Borenstein (1989) propôs analisar a forma como uma empresa aérea adquire poder de mercado, ou seja, maneiras de cobrar um preço superior ao vigente em concorrência perfeita e sustentá-lo ao longo do tempo, onde centrou a operação de empresas a partir de hubs. Embora esta hipótese não possa ser testada no caso brasileiro devido à inexistência de uma configuração típica de hub-andspoke, é válido ressaltar que em regiões metropolitanas com múltiplos aeroportos, 
o autor os considerou como mercados distintos. Esta distinção também foi utilizada por Bilotkach (2005), Oliveira e Huse (2005) e no presente trabalho. Da mesma forma que em Oliveira e Huse (2005), os objetos de análise são os aeroportos de Congonhas e de Guarulhos. Porém nesta análise, não são estudados os vôos unidirecionais (sem regresso), mas vôos bidirecionais com partidas da cidade de São Paulo.

Berry, Carnall e Spiller (1997) em seu estudo de companhias aéreas hubs e as implicações da heterogeneidade dos consumidores em relação às tarifas das passagens, capturou os cenários de turismo e viajantes a negócios. Nesse sentido, este trabalho empírico faz uma varredura em todas as passagens oferecidas pelas companhias aéreas pesquisadas para capturar os mesmos cenários, frente a todas as possibilidades de passagens que aparecem à vista.

\section{Metodologia}

Com a intenção de verificar a postura das empresas em relação às rotas de longos percursos, as três maiores companhias aéreas foram comparadas. Para isso foi feita uma coleta de dados para a TAM, Varig e GOL, através dos websites das próprias empresas. O ensaio foi realizado para viagens de ida, para todos os vôos non stop, com escala e/ou com conexão em rotas de longos percursos em doze pares de aeroportos (PDA) brasileiros. Os PDAs direcionais analisados foram: Congonhas-Belém, Belém-Congonhas, Guarulhos-Belém, Belém-Guarulhos, Congonhas-Manaus, Manaus-Congonhas, Guarulhos-Manaus, Manaus-Guarulhos, Congonhas-São Luís, São Luís-Congonhas, Guarulhos-São Luís, São Luís-Guarulhos.

As coletas realizaram-se nos dias 25, 26, 28 e 29 de maio de 2006, onde foram capturadas todas as possibilidades de vôo em cada rota. Em seguida, foram incorporados ao modelo diferentes perfis estilizados de consumidores, definidos como viajantes a negócios (mais inelástico a preços), e viajantes a lazer, do tipo "feriadão" ou "férias de julho" (mais elásticos a preços). Esta definição de tipos de consumidores permitiu, como em Bettini et al. (2005), a flexibilização de uma hipótese corriqueira nos estudos do setor aéreo, que é a hipótese do consumidor representativo. A seguir são apresentados detalhes dos três cenários gerados.

\subsection{Cenário 1: Tipicamente a negócios}

Para definir de forma real o comportamento deste tipo de consumidor numa rota de longa distancia, os autores realizam uma pesquisa exploratória com sete empresas diferentes, que apresentavam como trajeto de viagens a negócios, pelo menos um dos seis PDAs.

Com base na pesquisa, foi verificado que a grande maioria dos entrevistados compram a passagem com até 1 semana de antecedência e permanecem 1 semana no destino. Muitas vezes a viagem é feita em grupo e não um funcionário apenas. Notou-se também que as empresas que preferem agendar viagens pela TAM (maioria dentre as pesquisadas) têm como prioridade os horários dos vôos, enquanto as preferem a GOL priorizam o preço. Normalmente, existe uma pessoa responsável pela compra das passagens e de modo geral, a empresa escolhe ida e volta pela mesma companhia aérea.

Para completar a análise das respostas dos questionários, observou-se que numa viagem a negócios para rotas de longo percurso o funcionário aproveita o final de semana para lazer quando permanece no local de destino por mais de 5 dias. E em viagens que duram até 3 dias isto não ocorre. Quanto ao embarque e desembarque da cidade de São Paulo, os mesmos ocorrem de preferência, no aeroporto mais próximo da empresa. Assim, tendo como uma referência auxiliar as respostas obtidas pelas empresas, traçou-se o cenário 1 como aquele em que o tempo de antecedência da compra varia de 6 a 10 dias, a duração da permanência na cidade de destino é de 
7 dias e a passagem é comprada com partida no dia 4 de junho (domingo) e com retorno dia 11 de junho. (próximo domingo). Correspondendo ao típico viajante a negócios que embarca num curto prazo em relação à compra da passagem.

\subsection{Cenário 2: Tipicamente Lazer - "Feriadão"}

Os pesquisadores diagnosticaram, junto a algumas agências de viagens, que neste feriado prolongado existe um aumento de procura por estes destinos. Este cenário envolve a partida no dia 14 de junho de 2006 (quarta-feira, véspera do feriado de Corpus Christi) e o retorno no dia 18 de junho (domingo), com duração da permanência na cidade de destino de 4 dias. A antecedência da compra varia de 16 a 20 dias. Cenário tipicamente lazer por se tratar de uma data de viagem num feriado nacional, onde o passageiro pode programar a compra de passagem em torno de 20 dias antes da data do embarque.

\subsection{Cenário 3: Mês de Julho}

$\mathrm{Na}$ pesquisa exploratória observou-se, de forma unânime que o comportamento das empresas em relação ao mês de julho é indiferente se comparado com os demais meses do ano. Este cenário pode ser caracterizado como viagem a lazer e/ou viagem a negócios programados. A coleta acontece com pouco mais de um mês de antecedência, representando uma viagem a lazer planejada, bem como uma viagem a negócios programada com antecipação (caso de auditorias, consultorias, congressos e treinamentos, entre outros). Dessa forma tem-se a antecedência da compra de 34 a 37 dias e a duração da permanência na cidade de destino de 1 semana. A passagem é comprada para o dia 01 de julho (domingo) e com retorno dia 09 julho (próximo domingo).

Para cada um dos três cenários descritos acima, foram coletados os atributos: hora ENGEVISTA, v. 8, n. 1, p. 4-15, junho 2006 de partida, hora de chegada, duração do vôo, non stops e stops (escala e conexão), número do vôo, tipo de aeronave e preços para as viagens de ida e de volta nos seis PDAs já mencionados. É conveniente ressaltar que a decisão por coletar todos os vôos disponíveis em cada empresa, surgiu para evitar uma dedução prévia de que uma das empresas possui maior vantagem competitiva que outra. Isto é, se fossem coletadas apenas as tarifas mais baixas ou mais altas, poderíamos estar induzindo um resultado de que uma determinada empresa pratica preços mais baixos ou mais altos, sem observar todos os seus produtos oferecidos. Apesar de correr o risco de coletar uma passagem aérea que esteja, teoricamente para "preencher espaço", o que poderia dar algum grau de erro na análise, assim mesmo, o fruto dessa coleta nos induz a ter a percepção dada da empresa àquela possível passagem. Durante os quatro dias de coleta, obtivemos um total de 2923 observações.

\section{Modelagem Empírica dos Preços das Companhias Aéreas}

A pesquisa procurou verificar, por meio de um modelo de regressão múltipla, quais variáveis explanatórias $\mathrm{x}_{1}$, $\mathrm{x}_{2}, \mathrm{x}_{3}, \ldots, \mathrm{x}_{\mathrm{n}}$ possuem poder de explicação na composição dos preços $\mathrm{y}$ das passagens aéreas observadas. A cada variável $\mathrm{x}_{\mathrm{i}}$ está associado um coeficiente $\beta_{i}$ que representa a porcentagem de variação de y diante de uma variação em $\mathrm{x}_{\mathrm{i}}$. Segue a equação linear como descrita em Hill et al. (2003).

$$
y=\beta_{0}+\beta_{1} x_{1}+\beta_{2} x_{2}+\beta_{3} x_{3}+\ldots+\beta_{n} x_{n}+u
$$

No modelo em estudo foram utilizadas variáveis explicativas qualitativas. Foram atribuídas a elas, variáveis binárias, podendo-se reescrever a equação (1) da seguinte forma:

$$
y=\beta_{0}+\delta_{1} d_{1}+\delta_{2} d_{2}+\delta_{3} d_{3}+\ldots+\delta_{n} d_{n}+u
$$

Com a transformação das variáveis $x_{i}$ em $d_{i}$, os coeficientes $\beta_{i}$ são 
substituídos por $\delta_{\mathrm{i}}$. Devido à propriedade da variável binária em assumir valor igual a 1 ou $0, \delta$ i representa a variação de y diante da presença da variável dependente $d_{i}$. Variações essas que serão estimadas pelo modelo em estudo. Ao atributo que possuir mais de dois níveis, foi omitido um desses níveis. Com a omissão de uma variável binária, definese um grupo ou situação de referência. Os resultados deverão então ser interpretados tomando por base a característica de referência, isto é, os coeficientes das variáveis binárias representam diferenças do valor médio da variável dependente em relação a esse grupo. A não omissão acarretaria na soma das binárias igual a um vetor unitário, levando à colinearidade exata dos dados. O método dos mínimos quadrados ordinários (OLS) pressupõe que não há multicolinearidade perfeita entre as variáveis explicativas, uma vez que uma relação linear perfeita entre elas implicaria que seus coeficientes de regressão seriam indeterminados. (Bettini et al., 2005).

\subsection{Estatísticas Descritivas}

A Tabela 1 resume as médias de preços e preço/ $\mathrm{km}$ das passagens coletadas nas companhias aéreas. Observa-se que o preço médio da TAM é cerca de $17 \%$ maior que o preço médio da Gol, enquanto o preço médio da Varig é cerca de $10 \%$ menor que esta.

Tabela 1: Análise descritiva das médias de preços e preço/ km

\begin{tabular}{|c|c|c|c|c|c|}
\hline \multirow{2}{*}{$\begin{array}{c}\text { Cia } \\
\text { Aérea }\end{array}$} & \multicolumn{2}{|c|}{ Preço (R\$) } & \multicolumn{2}{c|}{$\begin{array}{c}\text { Preço/ km (R\$/ } \\
\mathrm{km})\end{array}$} & \multirow{2}{*}{$\begin{array}{c}\text { Freqüên } \\
\text { cia }\end{array}$} \\
\cline { 2 - 6 } & Média & $\begin{array}{c}\text { Desv. } \\
\text { Padrão }\end{array}$ & Média & $\begin{array}{c}\text { Desv. } \\
\text { Padrão }\end{array}$ & \\
\hline GOL & 788,22 & 271,30 & 0,2356 & 0,0905 & 495 \\
\hline TAM & 920,31 & 288,38 & 0,2985 & 0,0963 & 1906 \\
\hline VARIG & 710,81 & 186,66 & 0,2160 & 0,0669 & 522 \\
\hline
\end{tabular}

A Tabela 2 resume as médias de preços das passagens coletadas nas companhias ENGEVISTA, v. 8, n. 1, p. 4-15, junho 2006 aéreas, conforme cada cenário. Observase que a Gol compete com a TAM como companhia aérea de maior preço ofertado. A TAM apresenta os maiores preços para passagens que retornam para São Paulo nos três cenários e para ida apenas no terceiro cenário (em que a passagem é comprada com antecedência), logo, a Gol apresentou as tarifas mais caras para as saídas de São Paulo nos cenários 1 e 2; e a Varig teve os menores preços ofertados, com exceção dos retornos dos cenários 1 e 3 que foram da Gol.

Tabela 2: Médias de preços das passagens conforme cada cenário

\begin{tabular}{|c|c|c|c|c|}
\hline \multirow{4}{*}{ Cenários } & $\begin{array}{c}\text { Cia } \\
\text { Aérea }\end{array}$ & $\begin{array}{c}\text { Média de } \\
\text { Preço } \\
(\mathrm{R} \$)\end{array}$ & $\begin{array}{c}\text { Desvio } \\
\text { Padrão } \\
(\mathrm{R} \$)\end{array}$ & $\begin{array}{c}\text { Freqüênc } \\
\text { ia }\end{array}$ \\
\hline $\begin{array}{c}\text { Negócios } \\
\text { Ida }\end{array}$ & GOL & 935,94 & 262,89 & 88 \\
\cline { 2 - 5 } & TAM & 843,85 & 190,71 & 222 \\
\cline { 2 - 5 } & VARIG & 755,25 & 160,36 & 59 \\
\hline $\begin{array}{c}\text { Negócios } \\
\text { Volta }\end{array}$ & GOL & 598,34 & 253,66 & 68 \\
\cline { 2 - 5 } & TAM & 820,16 & 218,42 & 376 \\
\cline { 2 - 5 } Feriadão & VARIG & 628,91 & 120,08 & 98 \\
\cline { 2 - 5 } & GOL & 875,01 & 213,79 & 100 \\
\cline { 2 - 5 } & TAM & 847,70 & 208,94 & 374 \\
\hline \multirow{2}{*}{$\begin{array}{c}\text { Feriadão } \\
\text { Volta }\end{array}$} & GOL & 745,38 & 166,45 & 74 \\
\cline { 2 - 5 } & TAM & 1008,24 & 289,91 & 274 \\
\cline { 2 - 5 } & VARIG & 776,63 & 251,50 & 98 \\
\hline Mês Julho & GOL & 749,61 & 249,60 & 91 \\
\cline { 2 - 5 } Ida & TAM & 929,50 & 268,46 & 260 \\
\cline { 2 - 5 } & VARIG & 688,60 & 103,22 & 65 \\
\hline Mês Julho \\
Volta & GOL & 684,33 & 268,30 & 73 \\
\cline { 2 - 5 } & TAM & 1058,59 & 380,52 & 400 \\
\cline { 2 - 5 } & VARIG & 693,92 & 199,73 & 128 \\
\hline
\end{tabular}

A Tabela 3 resume as médias de preços das passagens coletadas nas companhias aéreas, conforme o tipo de rota. Em geral, observa-se que as companhias aéreas cobram passagens maiores para vôos com conexão e menores para vôos non stop. A exceção é a Varig que cobra preços menores para vôos com conexão, quando comparados com vôos com escala. Supõe-se que as passagens de vôos com conexão sejam mais caras devido ao aumento de custos operacionais; quanto a oferecer vôos non stop, a TAM é a única companhia aérea que não oferece vôos diretos nos pares de 
aeroportos estudados. Apenas 5\% dos vôos ofertados pela Gol são non stop, enquanto a Varig oferta 11,5\%; quanto aos vôos com conexão, $70 \%$ dos vôos da Gol nas rotas estudadas têm conexão, diante de $90 \%$ da TAM e $80 \%$ da Varig.

Tabela 3: Médias de preços das passagens conforme o tipo de rota

\begin{tabular}{|c|c|c|c|c|c|}
\hline \multirow{2}{*}{$\begin{array}{c}\text { Tipo de } \\
\text { Rota }\end{array}$} & \multirow[b]{2}{*}{ Cia Aérea } & \multirow{2}{*}{$\begin{array}{c}\text { Média de } \\
\text { Preço } \\
\text { (R\$) }\end{array}$} & \multirow{2}{*}{$\begin{array}{c}\text { Desvio } \\
\text { Padrão } \\
(\mathrm{R} \$)\end{array}$} & \multicolumn{2}{|c|}{ Freqüência } \\
\hline & & & & $\begin{array}{c}\text { Quantida } \\
\text { de }\end{array}$ & $(\%)$ \\
\hline \multirow{3}{*}{ Conexão } & GOL & 810,19 & 269,34 & 352 & 71,11 \\
\hline & TAM & 925,31 & 291,33 & 1728 & 90,66 \\
\hline & VARIG & 711,08 & 184,00 & 419 & 80,27 \\
\hline \multirow{3}{*}{ Escala } & GOL & 776,98 & 278,42 & 118 & 23,84 \\
\hline & TAM & 871,81 & 253,62 & 178 & 9,34 \\
\hline & VARIG & 820,90 & 192,76 & 43 & 8,24 \\
\hline \multirow{3}{*}{ Non stop } & GOL & 531,98 & 11,8 & 25 & 5,05 \\
\hline & TAM & - & - & - & - \\
\hline & $\overline{\text { VARIG }}$ & 629,97 & 160,84 & 60 & 11,49 \\
\hline
\end{tabular}

\subsection{Tratamento dos dados}

A metodologia utilizada neste trabalho foi a análise intra-rota para os pares de aeroportos, já mencionada anteriormente. A variável dependente a ser explicada foi normalizada para preço/ $\mathrm{km}$, a fim de garantir mais precisão na análise do preço em termos absolutos, que é fortemente determinado pela distância entre origem e destino. Acrescentaram-se deslocadores (variáveis dummies) para cada par de aeroportos (PDA) para medir o efeito específico de cada PDA pode ter devido a fatores como: renda dos viajantes, motivação da viagem, custos particulares da região e concentração ou competitividade no mercado.

O modelo pode ser interpretado da seguinte forma: $\beta_{0}$ representa $o$ intercepto, ou seja, o valor médio do preço/ km nas situações de referência; os demais parâmetros, estimados para as variáveis dummies, representam o fator de desconto ou acréscimo do preço/ km em relação à situação de referência diante da atuação da variável dummy em questão.

\subsection{Descrição das variáveis construídas}

ENGEVISTA, v. 8, n. 1, p. 4-15, junho 2006
As variáveis utilizadas na configuração do modelo foram geradas a partir da base de dados disponível. A variável dependente do modelo foi Preço_km, ou seja, o preço da passagem por quilômetro percorrido em $\mathrm{R} \$ / \mathrm{km}$. Abaixo segue uma lista das variáveis explicativas.

\subsubsection{Variáveis de cenário}

- Cenário1_origem_SP: Variável dummy representativa do cenário Negócios, partida no dia 04/06/06 (origem: São Paulo). Esta variável foi utilizada na base de referência;

- Cenário1_destino_SP: Variável dummy representativa do cenário Negócios, retorno no dia 11/06/06 (destino: São Paulo);

- Cenário2_origem_SP: Variável dummy representativa do cenário Feriadão, partida no dia 14/06/06 (origem: São Paulo);

- Cenário2_destino_SP: Variável dummy representativa do cenário Feriadão, retorno no dia 18/06/06 (destino: São Paulo);

- Cenário3_origem_SP: Variável dummy representativa do cenário Mês Julho, partida no dia 02/07/06 (origem: São Paulo);

- Cenário3_destino_SP: Variável dummy representativa do cenário Mês Julho, retorno no dia 09/06/06 (destino: São Paulo);

\subsubsection{Variáveis de share de freqüências de vôo da companhia aérea na rota}

- Share1: Variável dummy representativa da participação de mercado (market share) da companhia aérea na rota, caso esta estivesse dentro do intervalo $] 0 \%$, $25 \%$ ]. Esta variável foi utilizada na base de referência;

- Share2: Variável dummy representativa da participação de mercado (market share) da companhia aérea na rota, caso esta estivesse dentro do intervalo ]25\%, $50 \%]$ 
- Share3: Variável dummy representativa da participação de mercado (market share) da companhia aérea na rota, caso esta estivesse dentro do intervalo ]50\%, $75 \%]$;

- Share4: Variável dummy representativa da participação de mercado (market share) da companhia aérea na rota, caso esta estivesse dentro do intervalo $] 75 \%$, $100 \%]$;

4.3.3. Variáveis de duração de viagem: (variável que contém o número de horas de duração da viagem)

- Dur_rápida: Variável dummy representativa da duração da viagem, $00 \mathrm{~h}$ $<$ duração $<05 \mathrm{~h}$. Esta variável foi utilizada na base de referência;

- Dur média: Variável dummy representativa da duração da viagem, $05 \mathrm{~h}$ $<$ duração $<10 \mathrm{~h}$;

- Dur_longa: Variável dummy representativa da duração da viagem, duração > 10h;

\subsubsection{Variáveis de horário de saída}

- Madrugada: Variável dummy representativa do horário de saída, $00 \mathrm{~h}<$ hcheia_partida $<06 \mathrm{~h}$;

- Manhã: Variável dummy representativa do horário de saída, 06h $<$ hcheia_partida $<12 \mathrm{~h}$. Esta variável foi utilizada na base de referência;

- Tarde: Variável dummy representativa do horário de saída, $12 \mathrm{~h}<$ hcheia_partida $<18 \mathrm{~h}$;

- Noite: Variável dummy representativa do horário de saída, $18 \mathrm{~h}<$ hcheia partida $<24 \mathrm{~h}$;

\subsubsection{Variáveis de dia de coleta:}

- Dia 1: Variável dummy representativa do dia de coleta, 25/05/06;

- Dia 2: Variável dummy representativa do dia de coleta, 26/05/06;
- Dia 3: Variável dummy representativa do dia de coleta, 28/05/06. Esta variável foi utilizada na base de referência;

- Dia 4: Variável dummy representativa do dia de coleta, 29/05/06;

4.3.6. Variáveis de tamanho da aeronave: (variável que contém o número de assentos oferecidos para o aeroporto de destino)

- Avião_p: Variável dummy representativa do tamanho da aeronave, assentos $<100$;

- Avião_m: Variável dummy representativa do tamanho da aeronave, $100<$ assentos $<150$;

- Avião_g: Variável dummy representativa do tamanho da aeronave, $150<$ assentos $<200$. Esta variável foi utilizada na base de referência;

- Avião_gg: Variável dummy representativa do tamanho da aeronave, assentos $>200$;

- $\mathrm{n}$ assentos: tamanho da aeronave em número de assentos;

\subsubsection{Variáveis de PDAs:}

- Cgh bel: Variável dummy representativa do PDA, Congonhas Belém;

- Cgh_mao: Variável dummy representativa do PDA, Congonhas Manaus. Esta variável foi utilizada na base de referência;

- Cgh_slz: Variável dummy representativa do PDA, Congonhas - São Luís;

- Gru_bel: Variável dummy representativa do PDA, Guarulhos Belém;

- Gru_mao: Variável dummy representativa do PDA, Guarulhos Manaus;

- Gru_slz: Variável dummy representativa do PDA, Guarulhos - São Luís; 
- Bel_cgh: representativa

Congonhas;

- Bel_gru: representativa

Guarulhos;

- Mao cgh: representativa

Congonhas;

- Mao gru: representativa Guarulhos;

- Slz_cgh: representativa do PDA, São Luís Congonhas;

- Slz_gru: Variável dummy representativa do PDA, São Luís Guarulhos;

\subsubsection{Variáveis de tipo de rota (stops):}

- Conexão: Variável dummy representativa do tipo de rota, para conexões;

- Escala: Variável dummy representativa do tipo de rota, para escalas;

- Non_stop: Variável dummy representativa do tipo de rota, para vôos sem paradas. Esta variável foi utilizada na base de referência;

\subsubsection{Variáveis de companhia aérea:}

- GOL: Variável dummy representativa da companhia aérea GOL Esta variável foi utilizada na base de referência para possibilitar a comparação dos preços das demais companhias;

- TAM: Variável dummy representativa da companhia aérea TAM;

- Varig: Variável dummy representativa da companhia aérea Varig.

\section{Discussão dos Resultados}

A Tabela 4, a seguir, apresenta os resultados do modelo estimado.

Algumas importantes inferências sobre o padrão de precificação das ENGEVISTA, v. 8, n. 1, p. 4-15, junho 2006 companhias aéreas brasileiras podem ser então efetuadas. Em primeiro lugar, no que tange às variáveis de cenário, tem-se que os retornos para São Paulo possuem preços em média maiores do que as idas; além disso, os preços pagos pelos viajantes tipicamente a negócios (Cenário 1) são, em geral, maiores do que os preços para os viajantes a lazer, quer seja para o feriadão, quer seja para as férias de julho (respectivamente, Cenários 2 e 3 ).

Quanto às variáveis de market share da companhia aérea na rota, tem-se que, tomando por base de comparação a variável share1 - a participação nas freqüências de vôo na rota inferior a $25 \%$ - os preços das passagens em que o share está entre $25 \%$ e $75 \%$ são mais elevados. Isso retrata o efeito da dominância do mercado pela companhia aérea e também uma maior qualidade e diferenciação do produto associada a um maior percentual de freqüências de vôo oferecidas.

Por outro lado, quando o share da empresa é maior do que $75 \%$, foi observado um sinal negativo e estatisticamente significativo, o que pode ser indicativo de uma maior pressão para preencher assentos vazios. Importante salientar, contudo, que os efeitos das variáveis representativas de share podem ser prejudicados pelo fato de ser esta uma variável endógena, ao invés de exógena, no modelo de regressão.

Tabela 4: Valores dos coeficientes das variáveis obtidos nas regressões 


\begin{tabular}{|c|c|}
\hline Variável & $\begin{array}{c}\text { preco_km } \\
(\mathrm{R} \$ / \mathbf{k m})\end{array}$ \\
\hline Cenário1_destino_SP & $0,0345 * * *$ \\
\hline Cenário2_origem_SP & $-0,0092 *$ \\
\hline Cenário2_destino_SP & $0,0249 * *$ \\
\hline Cenário3_origem_SP & $-0,0062$ \\
\hline Cenário3_destino_SP & $0,0222 *$ \\
\hline share2 & $0,0177 * * *$ \\
\hline share3 & $0,0136^{*}$ \\
\hline share4 & $-0,0288 * * *$ \\
\hline duração & - \\
\hline dur_média & $0,0311 * * *$ \\
\hline dur_longa & $0,0729 * * *$ \\
\hline madrugada & $0,0407 * * *$ \\
\hline tarde & $0,0090^{*}$ \\
\hline noite & $0,0374 * * *$ \\
\hline dia 1 & 0,0045 \\
\hline dia 2 & 0,0047 \\
\hline dia 4 & $0,0113 * * *$ \\
\hline n_assentos & - \\
\hline Avião_p & $-0,0280 * * *$ \\
\hline Avião_m & $-0,0073$ \\
\hline Avião_gg & $-0,0219 * *$ \\
\hline bel_cgh & $0,0416^{* * *}$ \\
\hline bel_gru & $0,0708 * * *$ \\
\hline cgh_bel & $0,0167 * *$ \\
\hline gru_bel & $0,0409 * * *$ \\
\hline cgh_slz & $0,0784 * * *$ \\
\hline gru_slz & $0,0500 * * *$ \\
\hline slz_cgh & $0,0729 * * *$ \\
\hline slz_gru & $0,0694 * * *$ \\
\hline mao_cgh & $-0,0129$ \\
\hline mao_gru & $-0,0414 * * *$ \\
\hline gru_mao & $-0,0201 *$ \\
\hline conexao & $-0,0106$ \\
\hline escala & 0,0044 \\
\hline tam & $0,0305 * * *$ \\
\hline varig & $-0,0187 * * *$ \\
\hline constante & $0,1671 * * *$ \\
\hline $\mathbf{R}^{2}$ ajustado & 0,3370 \\
\hline N. Observações & 2923 \\
\hline
\end{tabular}

Com relação às variáveis de duração de viagem, tem-se que, tomando por referência a variável dur_rapida, representativa de viagens com menos de $5 \mathrm{~h}$ de duração, os preços das passagens para viagens de duração média e longa são maiores, de acordo com a expectativa $a$ priori. Com relação às variáveis de horário de saída, e, tomando por referência a variável manhã, representativa do horário de saída entre $06 \mathrm{~h}$ e 12h (hora-cheia), chegou-se à conclusão de que as passagens compradas com saídas agendadas para a madrugada e a noite são, em geral, mais caras. Isto foi considerado intuitivo, dado que, em vôos mais longos, tanto os passageiros com viagens a negócios quanto os com viagem durante $\mathrm{o}$ feriadão, podem ter necessidade de chegar mais cedo ao destino - seja por conta de um compromisso, reunião, ou mesmo, no caso do turista, para aproveitar o máximo o período de estadia. De qualquer maneira, trata-se de um resultado ilustrativo importante, dado que os vôos noturnos, do tipo "corujão", são usualmente associados a preços mais baixos.

Outros resultados importantes foram os seguintes. Primeiramente, tomando por referência a variável cgh_mao, representativa de viagens de Congonhas para Manaus, os preços das passagens para os demais pares de aeroportos que envolvem Manaus são mais baixos. Porém, para os demais pares de aeroportos, que não envolvem Manaus, os preços são mais altos. Em geral, vôos com partida ou pouso em Congonhas são mais caros, com exceção de vôos relativos a São Paulo-Belém. Com relação às companhias aéreas, e tendo-se como por referência a variável Gol, representativa da companhia aérea Gol Linhas Aéreas, os preços das passagens da TAM são significativamente maiores (o coeficiente estimado tam é $+0,0305$ e significativo); por outro lado, constatou-se que a Gol não é, em média, a opção low fare (tarifas baixas) nos mercado analisados, dado que o preços das passagens da Varig são menores, tudo o mais mantido constante. De fato, o coeficiente estimado da variável Varig foi igual a $-0,0187$ (e significante), o que é indicativo de que uma empresa em dificuldades financeiras e em estado pré-falimentar (sob o amparo da Lei de Recuperação Judicial) pode apresentar comportamento fortemente competitivo no mercado, sobretudo por conta da necessidade de geração de fluxo de caixa e da proteção contra credores.

\section{5- Considerações Finais}

O presente trabalho visou estudar os padrões de precificação das companhias aéreas nacionais em um 
mercado ainda pouco investigado pelos trabalhos da literatura nacional: as rotas domésticas de longo percurso. Dado que as estratégias de marketing das companhias aéreas em geral fazem, na sua abordagem, distinção entre tipos de consumidor, buscou-se também incorporar à analise um estudo da precificação das mesmas sob a ótica de cenários alternativos de consumo, os tipos de passageiros - "negócios", "lazerferiadão" e "férias de julho". Desta forma, foram coletados dados dos websites das companhias aéreas nacionais, visando-se a constituição de uma base de dados representativa da competição entre as operadoras, e com objetivos de estimação de uma equação de preços.

A partir das regressões geradas, e controlando-se por diversos efeitos deslocadores de preços intra e inter-rotas, verificou-se que as tarifas são, em geral, maiores para os viajantes a negócios, maiores para o caso de retorno a São Paulo, maiores para vôos com partidas à noite e de madrugada, e maiores para a Tam e Gol - em comparação com a Varig. Alguns desses resultados se contrapõem às análise tradicionais ou mesmo ao senso-comum relacionado à precificação do setor aéreo, o que demonstra a relevância de estudos desta natureza, e que levem em consideração a especificidade inerente aos diversos tipos de mercados aéreos bem como aos possíveis tipos de consumidor.

\section{Agradecimento}

O último autor agradece o apoio da FAPESP, Fundação de Amparo à Pesquisa do Estado de São Paulo.

\section{Referências}

Berry, S. T. (1990) Airport Presence as Product Differentiation. The American Economic Review, vol. 80, p. 394-399.

Berry, S. T., Carnall, M. e Spiller, P. T. (1997) Airlines Hubs: Costs, Markups and Implications of Customer Heterogeneity.

ENGEVISTA, v. 8, n. 1, p. 4-15, junho 2006
Bettini, H. F. A. J., Lovadine, D., Todesco. F.; Vassallo, M. D. e Oliveira, A. V. (2005) Descontos em Tarifas Aéreas e seus Determinantes: um estudo de caso aplicado à compra de passagens pela Internet em rotas selecionadas. XIX Congresso de Pesquisa e Ensino em Transportes. Recife, Brasil.

Bilotkach, V. (2006). Understanding Price Dispersion in the Airline Industry: Capacity Constraints and Consumer Heterogeneity. In: Lee, D. (eds.) Advances in Airline Economics, Vol. 1, Ed. Elsevier.

Borenstein, S. (1989). Hubs and High Fares: Dominance and Market Power in the U.S. Airline Industry. Rand Journal of Economics vol. 20, p. 344-365.

DAC. (2004). Anuário do Transporte Aéreo: Dados econômicos, Departamento de Aviação Civil - Subdepartamento de Serviços Aéreos, Divisão de Assuntos Econômicos, vol. II.

Evans, W. N. e Kessides, I.N. (1993). Structure, conduct, and performance in the deregulated airline industry. Southern Economic Journal vol. 59, p. 450-467.

Hill, R., Griffiths, W. e Judge, G. (2003). Econometria. Ed. Saraiva, São Paulo.

Soares de Mello, J. C., Gomes, E., Gomes, L. F, Biondi Neto, L. e Leta, F. (2003) Seleção de Rota Aéreas com o Uso do Apoio Multicritério à Decisão. Engevista, Vol. 5, N. 10.

Oliveira, A. V. M. e Huse, C. (2005). Localized Competitive Advantage and Price Reactions to Entry: Full-Service vs. Low-Cost Airlines in the Brazilian Market. Documento de Trabalho N. 010 - Acervo Científico do Núcleo de Estudos em Competição e Regulação do Transporte Aéreo (NECTAR). São José dos Campos, SP. Disponível em http://www.nectar.ita.br/

Palladino, R. (2005). O avanço das empresas low cost, low fare revoluciona o transporte aéreo mundial. Turismo em Número, vol. 48, p. 10-19.

Pasin, J. e Lacerda, S. (2003). A Reestruturação do Setor Aéreo e as 
Alternativas de Política para a Aviação Comercial no Brasil. Revista do BNDES vol. 10, p. 217-240.

Marchetti, D.; Souza, R.; Ávila, J. e Castro, M. (2001). Aspectos de Competitividade do Setor Aéreo (Modal Aéreo II). Informe Infra-Estrutura Banco Nacional de Desenvolvimento Econômico e Social - BNDES 42. 